Ensino, Saúde e Ambiente - V10 (1), pp. 218-237, Abril. 2017

\title{
UMA PRÁTICA DE EDUCAÇÃO AMBIENTAL PARA DISCUTIR SUSTENTABILIDADE NO MANGUEZAL DE NOVA ALMEIDA DO ESTADO DO ESPÍRITO SANTO
}

\section{AN ENVIRONMENTAL EDUCATION PRACTICE TO DISCUSS SUSTAINABILITY IN THE NOVA ALMEIDA MANGROVE OF ESPÍRITO SANTO STATE}

\author{
Katiuscia Soares Viana Rocha ${ }^{1,2}$; Sidnei Quezada Meireles Leite ${ }^{2}$ \\ ${ }^{1}$ Secretaria Municipal de Educação de Serra do Estado do Espírito Santo. E-mail: \\ katiusciavianarocha@gmail.com \\ ${ }^{2}$ Programa de Pós-graduação em Educação em Ciências e Matemática, Centro de Referência em \\ Formação e Educação a Distância do Instituto Federal do Espírito Santo. E-mail: \\ sidneiquezada@gmail.com
}

\section{RESUMO}

O objetivo deste trabalho foi o de estudar os aspectos metodológicos das práticas ambientais à luz das Diretrizes Curriculares Nacionais para a Educação Ambiental, promovidas por um projeto escolar denominado "Manguezal", com a participação voluntária de 19 estudantes, filhos dos pescadores, do ensino fundamental público da cidade de Serra, no Estado do Espírito Santo, Brasil. Este projeto escolar foi realizado em 2012 e consistiu numa aula de campo organizada em três etapas, isto é, pé-campo, campo e pós-campos, realizado no Manguezal de Nova Almeida, na mesma cidade da escola. Tratou-se de uma investigação qualitativa de um projeto escolar de educação ambiental articulado à disciplina de ciências naturais do ensino fundamental. Os dados foram produzidos a partir de observações, aulas de campo no manguezal, rodas de conversa e questionários aplicados aos sujeitos. A análise dos aspectos metodológicos da educação ambiental indicou a articulação de saberes escolares, populares e científicos a partir das temáticas de "manguezal", "pesca artesanal" e "sustentabilidade", perpassando por conteúdos de ciências naturais, aspectos tecnológicos, sociocientíficos, socioeconômicos, sócio-históricos, socioculturais e socioambientais. A perspectiva da totalidade na prática educativa promoveu uma visão além dos aspectos ecológicos, enfatizando para os estudante a importância do contexto da pesca artesanal.

Palavras-chave: educação em ciências, ensino fundamental, aula de campo, sustentabilidade, manguezal, educação não formal, educação ambiental.

\begin{abstract}
The objective of this work was to study the methodological aspects of environmental practices in the light of the National Curricular Guidelines for Environmental Education of Brazil, promoted by a school project called "Manguezal", in english mangrove, with the voluntary participation of 19 students of elementary school, children of fishermen, in Serra city, in Espírito Santo State, Brazil. This school project was carried out in 2012 and consisted of a field class organized in three stages, that is, pre-field, field and postfields, held in the "Nova Almeida Mangrove", in the same city of the school. It was a qualitative investigation of a school project of environmental education articulated to the discipline of natural sciences of elementary education. The data were produced from observations, field classes in the mangrove, conversation wheels and questionnaires applied to the subjects. The analysis of the methodological aspects of environmental education indicated the articulation of scholarly, popular and scientific knowledge from
\end{abstract}


the themes "Nova Almeida Mangrove ", "Artisanal Fishing" and "Sustainability", permeating natural sciences contents, technological, socio-scientific, socio-economic, socio-historical, socio-cultural and socioenvironmental aspects. The perspective of totality in the educational practice promoted a vision beyond the ecological aspects, emphasizing to the students the importance of the context of the artisanal fishing.

Keywords: science education, elementary education, field class, sustainability, mangrove, non-formal education, environmental education.

\section{Introdução}

A promulgação da política nacional de educação ambiental (BRASIL, 1999) prevê a promoção da educação ambiental em todos os níveis/modalidades de ensino e em outros espaços sociais não formais. Com a Lei Estadual № 9.265, de 15 de julho de 2009, o Estado do Espírito Santo instituiu sua política estadual de educação ambiental (ESPÍRITO SANTO, 2009), baseado em alguns princípios com uma concepção de ambiente em sua totalidade, isto é, com uma concepção de ambiente que vai além da perspectiva ecológica, voltada para a cultura da sustentabilidade socioambiental.

Santos (1977), em seu livro "A totalidade do Diabo: Economia Espacial", faz uma grande crítica ao modelo capitalista e um alerta sobre seus efeitos na sociedade. Usando o termo "totalidade do diabo", o autor buscou fazer alusão aos terríveis efeitos do sistema econômico imposto à sociedade, produzindo desigualdades sociais, o mau aproveitamento do espaço territorial, a concentração de renda, a busca por mais lucro e o abandono aos pobres entre outros e algumas empresas dividem o trabalho de produção de modo desumano. Ao pensar nesse conceito de totalidade, procuramos estender o conceito de sustentabilidade na perspectiva da totalidade, considerando uma prática pedagógica desenvolvida num espaço de educação não formal, isto é, numa prática além da sala de aula. De acordo com Sachs (1993), é importante desenvolver uma visão holística dos problemas da sociedade, em contraposição da visão reducionista focada apenas na gestão dos recursos naturais.

De acordo com Leff (2002), o conceito de sustentabilidade surgiu nas últimas décadas do século XX, para traduzir várias ideias e preocupações devido à gravidade dos problemas ambientais e econômicos e causavam, e ainda causam, riscos às condições de vida no planeta. A Conferência de Estocolmo de 1972, realizada pela organização das Nações Unidas com a participação de 113 países, em Estocolmo, capital da Suécia. Talvez, esse evento tenha sido o grande marco inicial para se discutir sustentabilidade, abordando problemas ambientais decorrentes da poluição atmosférica, crescimento populacional e crescimento versus desenvolvimento. Durante a conferência foi concebido um importante documento político chamado "Declaração da Conferência das Nações Unidas sobre o Meio Ambiente Humano" (ONU, 1972).

Neste trabalho, buscamos envolver uma comunidade pesqueira do rio Reis Magos na cidade de Serra no Estado do Espírito Santo, que desemboca no mar, entre Nova Almeida (Município de Serra) e Praia Grande (Município de Fundão), seu estuário forma um manguezal, que é um dos ecossistemas associados à Mata Atlântica. Por ser um ambiente rico e diversificado, consiste num importante berço de informações históricas e socioambientais, em função das diferentes localizações geográficas (ROCHA; LEITE, 2014). Nas rodas de conversa realizadas previamente com os estudantes da escola de ensino fundamental, percebemos que eles, ao serem entrevistados, sentiam-se envergonhados por serem filhos de pescadores e não relatavam as atividades pesqueiras realizadas pelos seus pais. Então, produzimos um 
projeto escolar chamado de "Manguezal", desenvolvido no contraturno escolar, em articulação com a disciplina de ciências naturais, articulando saberes escolares, populares e científicos a partir das temáticas de "manguezal", "pesca artesanal" e "sustentabilidade".

Para organizar o estudo científico, consideramos os princípios estabelecidos nas Diretrizes Curriculares Nacionais para a Educação Ambiental (BRASIL, 2012), construídos a partir da Lei Federal № 9.795/1999, com os quais produzimos o encadeamento da análise metodológica do projeto escolar. Para isso, utilizamos os seis princípios norteadores das DCNEA como categorias de análise, a saber: I - totalidade como categoria de análise fundamental em formação, análises, estudos e produção de conhecimento sobre o meio ambiente; II - interdependência entre o meio natural, o socioeconômico e o cultural, sob o enfoque humanista, democrático e participativo; III - vinculação entre ética, educação, trabalho e práticas sociais na garantia de continuidade dos estudos e da qualidade social da educação; IV - articulação na abordagem de uma perspectiva crítica e transformadora dos desafios ambientais a serem enfrentados pelas atuais e futuras gerações, nas dimensões locais, regionais, nacionais e globais; e V - respeito à pluralidade e à diversidade, seja individual, seja coletiva, étnica, racial, social e cultural, disseminando os direitos de existência e permanência e o valor da multiculturalidade e plurietnicidade do país e do desenvolvimento da cidadania planetária.

Durante as reuniões do grupo de investigação, foram levantados alguns questionamentos sobre as potencialidades de educação ambiental. De que maneira uma intervenção pedagógica poderia ser desenvolvida articulando o espaço escolar e não escolar, para debater a sustentabilidade na perspectiva da totalidade? De que maneira os aspectos da pescaria artesanal e temática "Manguezal" poderiam ser entrelaçados aos conteúdos programáticos de ciências naturais? De que maneira os aspectos da sustentabilidade local e regional poderiam ser debatidos num projeto escolar? Vale lembrar que as perguntas servem como eixo condutor do trabalho, embora, algumas vezes, não se consiga respondê-las completamente. Segundo Gil (2009, p. 59), as questões surgidas para o pesquisador servem como lembretes para conduzir entrevistas e observações, entre outras formas de coleta de dados.

Portanto, o objetivo deste trabalho foi o de estudar os aspectos metodológicos da prática ambiental à luz das Diretrizes Curriculares Nacionais para a Educação Ambiental, promovidas por um projeto escolar denominado "Manguezal", com a participação voluntária de 19 estudantes, filhos dos pescadores, do ensino fundamental público da cidade de Serra, no Estado do Espírito Santo, Brasil.

\section{Metodologia}

Esta investigação qualitativa foi planejada à luz de Gil (2014) sobre uma intervenção pedagógica de educação ambiental, abordando a temática de sustentabilidade na perspectiva da totalidade. Numa tentativa de compreensão desta investigação, abraçamos a ideia de uma pesquisa-ação por ser uma estratégia metodológica de pesquisa social, o que segundo Thiollent $(2011$, p. 22), [...] o objeto de investigação não é constituído pelas pessoas e sim pela situação social e pelos problemas de diferentes naturezas encontrados nesta situação. Os dados foram produzidos a partir de observações dos investigadores, rodas de conversa, anotações feitas pelos estudantes no diário de bordo e fotografias produzidas ao longo da prática pedagógica. Na tabela 1 está apresentado um resumo das técnicas e instrumentos empregados na coleta de dados durante a intervenção pedagógica. Neste trabalho, 
procuramos apresentar uma análise fenomenológica da intervenção pedagógica de educação ambiental (Gil, 2009).

Quadro 1: Resumo das técnicas e instrumentos de coleta de dados empregados durante a investigação do projeto escolar "Manguezal".

\begin{tabular}{|l|l|l|}
\hline Investigação & Técnicas & Instrumentos \\
\hline \multirow{4}{*}{$\begin{array}{l}\text { Investigação } \\
\text { Qualitativa } \\
\text { Tipo: Pesquisa-ação. }\end{array}$} & Observações & Anotações no diário de bordo do investigador. \\
\cline { 2 - 3 } & Inquéritos & $\begin{array}{l}\text { Questionários e rodas de conversa feitas na forma de } \\
\text { entrevistas de grupo focal. }\end{array}$ \\
\cline { 2 - 3 } & Imagens & Fotografias como registro dos momentos. \\
\cline { 2 - 3 } & Relatos escritos & $\begin{array}{l}\text { Anotações produzidas pelos alunos em processo } \\
\text { colaborativo (produção textual). }\end{array}$ \\
\hline
\end{tabular}

As observações feita pelos autores durante a pesquisa foram materializadas na forma de diário de pesquisa de acordo com Barbasa e Hess (2010), próprio para os estudos fenomenológicos, que segundo os autores, [...] da perspectiva fenomenológica, os acontecimentos não podem ser considerados como fechados em si, enquanto realidades objetivas. Fazendo parte de sua própria temporalidade, a realidade é uma construção precária, provisória, fenomenal, como percepção dos fenômenos percebidos pela consciência ( $p$. 9). As rodas de conversa foram realizadas na forma de entrevistas de grupo focal, o que segundo Gatti (2005, p. 13), [...] o trabalho com grupos focais oferece boa oportunidade para o desenvolvimento de teorizações em campo, a partir do ocorrido e do falado.

A investigação foi autorizada pela Secretaria Municipal de Educação da Serra do Estado do Espírito Santo. Buscamos seguir todas as recomendações do Comissão Nacional de Ética em Pesquisa - CONEP/MS, com a autorização da diretora da escola, a identidade dos sujeitos foi preservada para evitar a exposição dos mesmos e houve o consentimento para o uso do depoimento oral e escrito dos sujeitos, além da autorização do uso da imagem. Os sujeitos da pesquisa foram 19 estudantes, com idade de 13 a 15 anos com adesão voluntária, sendo 12 meninas e 7 meninos, de duas turmas da disciplina de ciências naturais de uma escola da Rede Municipal de Educação Básica da Serra do Estado do Espírito Santo.

O planejamento da aula de campo abordando a pesca artesanal e o manguezal, foi baseada em Seniciato e Cavassan (2004) e Campos (2015), abordando aspectos socioeconômicos da pesca da região de Nova Almeida, no município de Serra, no Estado do Espírito Santo. Embora essa intervenção pedagógica fosse parte de um projeto maior, neste trabalho nos limitamos a discutir os dados referentes à aula de campo. A prática pedagógica foi realizada de outubro de 2012 a fevereiro de 2013, com encontros semanais de 120 minutos, além das visitas guiadas no manguezal de Serra, Espírito Santo.

Organizamos a análise metodológica do projeto escolar com base nos princípios estabelecidos nas Diretrizes Curriculares Nacionais para a Educação Ambiental (BRASIL, 2012), construídos a partir da Lei Federal № 9.795/1999. Os aspectos metodológicos da aula de campo foram analisados com base em Seniciato e Cavassan (2004) e Campos (2015). A análise dos aspectos da sustentabilidade na perspectiva da totalidade foi realizada com base em Sachs (1993) e Santos (1977). Os aspectos da educação CTS/CSTA e temas sociocientíficos foram analisados com base em Aikenhead (2009), Santos e Auler (2011), Vilches, Gil-Pérez e Praia (2011), Reis e 
Galvão (2008) e Sadler (2011). A análise dos aspectos pedagógicos da educação não formal foi baseada nos pressupostos de Gohn (2006, 2010).

\section{A aula de campo e os princípios da educação ambiental}

Com base na Lei Federal № 9.795/1999, que estabeleceu a política de educação ambiental em âmbito nacional, o Estado do Espírito Santo, por meio da Lei Estadual № 9.265, de 15 de julho de 2009, instituiu a sua política estadual de educação ambiental (ESPÍRITO SANTO, 2009). Essa lei apresenta os princípios para a educação ambiental, da seguinte maneira: 1 - o enfoque humanista, perspectiva sistêmica, processo democrático e participativo; 2 - a concepção do meio ambiente em sua totalidade; 3 - o pluralismo de ideais e concepções pedagógicas, na perspectiva da multidisciplinar, interdisciplinar e transdisciplinaridade; 4 - a vinculação entre a ética, a educação, o trabalho, a democracia participativa e as práticas socioambientais; 5 - entre outros princípios voltados para a cultura da sustentabilidade socioambiental. Buscamos perpassar por estes princípios no processo de organização da prática ambiental construída para o estudo desenvolvido.

Num estudo preliminar, realizamos algumas rodas de conversa com os estudantes da escola de ensino fundamental, quando percebemos um distanciamento entre os relatos apresentados por eles, filhos de pescadores, e a realidade da comunidade pesqueira, cujas atividades artesanais de pesca eram desenvolvidas pelos seus pais. Então, inspirado na Lei Federal № 9.795/1999, e na Lei Estadual № 9.265/2009, produzimos um projeto escolar, chamado de "Manguezal", contendo uma aula de campo desenvolvida no contraturno escolar, em articulação com a disciplina de ciências naturais. O planejamento metodológico foi baseado numa aula de campo abordando as temáticas de "manguezal", "pesca artesanal" e "sustentabilidade", organizada em três etapas, i.e., pré-campo, campo e pós-campo (SENICIATO; CAVASSAN, 2004; CAMPOS, 2015), devido à relevância socioeconômica da pesca da região de Nova Almeida no município de Serra, no Estado do Espírito Santo (quadro 2).

O manguezal, que também é chamado de mangue ou mangal (apesar destes serem os termos referentes a sua vegetação), é um ecossistema costeiro, de transição entre os ambientes terrestre e marinho, caracterizada por ser uma zona úmida localizada em regiões tropicais e subtropicais. É um ambiente localizado às margens de baías, enseadas, barras, desembocaduras de rios, lagunas e reentrâncias costeiras, onde haja encontro das águas de rio com o mar (ALVES, 2001).

O projeto escolar "Manguezal" teve quatro etapas, a saber: (1) planejamento e divulgação; (2) oficinas formativas; (3) desenvolvimento; e (4) a conclusão com um seminário final. As aulas de campo facilitam a interação dos estudantes com o meio ambiente em situações reais aguçando a busca pelo saber, além de estreitar as relações entre estudante/professor (VIVEIRO; DINIZ, 2009). Segundo os autores, em ambiente natural, é possível agrupar e relacionar os diferentes saberes - escolares, científicos e populares - dando possiblidade de criar canais de interlocução entre a escola, a academia e a comunidade. Corroborando essas ideias, Seniciato e Cavassan (2004) ressaltam que [...] o desenvolvimento das aulas de ciências e ecologia num ecossistema terrestre natural favorece a manifestação de sensações e emoções nos alunos, as quais normalmente não se manifestariam durante as aulas teóricas. Os autores enfatizam que as sensações surgidas durante a aula de campo, relacionam-se às condições abióticas do ambiente - como o frescor e o calor - e àquelas ligadas aos fatores bióticos, como o reconhecimento de sons, odores, cores, formas e texturas. 
Quadro 2: Resumo do planejamento da aula de campo abordando a educação ambiental, a pesca artesanal e o manguezal de Nova Almeida de Serra, Espírito Santo, Brasil.

\begin{tabular}{|c|c|c|}
\hline $\begin{array}{l}\text { Aula de } \\
\text { Campo }\end{array}$ & Objetivo & Atividade \\
\hline $\begin{array}{l}\text { Etapa I } \\
\text { Pré-Campo } \\
\text { (4 horas) } \\
\text { Outubro/12 }\end{array}$ & $\begin{array}{l}\text { Discutir a proposta } \\
\text { da aula de campo } \\
\text { na comunidade de } \\
\text { pesca artesanal, rio } \\
\text { Reis Magos e o } \\
\text { Manguezal. } \\
\text { Articular conteúdos } \\
\text { de ciências da } \\
\text { natureza com a } \\
\text { educação } \\
\text { ambiental. }\end{array}$ & $\begin{array}{l}\text { Durante o mês de outubro de } 2012 \text {, foram realizadas } 4 \text { aulas com } \\
\text { duração de } 60 \text { min cada, para tratar de conteúdos de educação } \\
\text { ambiental e de ciências naturais, de forma interdisciplinar e } \\
\text { transdiscipinar, perpassando por conteúdos de geografia, história, } \\
\text { biologia, química, física, matemática, sociologia e filosofia. Foi } \\
\text { discutida a atitudes e procedimentos durante a viagem de barco, } \\
\text { como os equipamentos para realizar a investigação, normas de } \\
\text { conduta e segurança na embarcação. Também, foi abordado o uso } \\
\text { do diário de bordo e fotografias para anotação dos momentos da } \\
\text { aula de campo. } \\
\text { Avaliação } 1 \text { (Individual). Questionário e produção textual sobre } \\
\text { os debates. }\end{array}$ \\
\hline $\begin{array}{l}\text { Etapa II } \\
\text { Campo } \\
(4 \text { horas }) \\
\text { Novembro/12 }\end{array}$ & $\begin{array}{l}\text { Visitar o rio Reis } \\
\text { Magos e o } \\
\text { Manguezal de Nova } \\
\text { Almeida. Coletar } \\
\text { dados por meio de } \\
\text { fotografias, } \\
\text { coletagem de } \\
\text { materiais, para } \\
\text { analisar as } \\
\text { potencialidades } \\
\text { ambientais. }\end{array}$ & $\begin{array}{l}\text { No dia } 01 \text { de novembro de 2012, as } 9 \text { h os estudantes embarcaram } \\
\text { no barco na Praça dos Pescadores no Distrito de Nova Almeida, } \\
\text { Serra, Espírito Santo. Os estudantes efetuaram registros das } \\
\text { evidências com o reconhecimento do rio Reis Magos. Durante o } \\
\text { trajeto os estudantes fizeram anotações das observações e } \\
\text { surgiram questionamentos a respeito da estrutura do ecossistema, } \\
\text { ocupação humana desordenada e impactos ambientais negativos. } \\
\text { Avaliação } 2 \text { (Grupo). Relatório da visita técnica. }\end{array}$ \\
\hline $\begin{array}{l}\text { Etapa III } \\
\text { Pós-Campo } \\
\text { (4 horas) } \\
\text { Dezembro/12 } \\
\text { a } \\
\text { Fevereiro/13 }\end{array}$ & $\begin{array}{l}\text { Roda de conversa } \\
\text { sobre a aula de } \\
\text { campo. Síntese e } \\
\text { produção textual } \\
\text { sobre a intervenção } \\
\text { pedagógica. }\end{array}$ & $\begin{array}{l}\text { Durante dezembro de } 2012 \text { a fevereiro de } 2013 \text {, foram realizadas } \\
\text { rodas de conversa com duração de } 120 \text { min cada. Os estudantes } \\
\text { preencheram um formulário contendo observações do campo, } \\
\text { compartilharam observações, tudo guiado por projeções de } \\
\text { fotografias e slides apresentados pela professora. Foram } \\
\text { abordadas algumas características do ecossistema e a atividade } \\
\text { artesanal pesqueira. } \\
\text { Avaliação } 3 \text { (Grupo). Relatório da prática pedagógica. }\end{array}$ \\
\hline
\end{tabular}

Na figura 1 está apresentado o mapa de localização da escola municipal e o rio Reis Magos desemborcando no distrito de Nova Almeida, na cidade de Serra do Estado do Espírito Santo, Brasil, onde a aula de campo foi realizada com os estudantes do ensino fundamental. A escola municipal fica localizada bem perto do rio Reis Magos e uma boa parte dos estudantes é filho dos pescadores, moradores da região de Nova Almeida (Serra/ES) e Praia Grande (Fundão/ES). Foram realizada observações das construções de casas de forma desordenada, testes químicos com a água, coleta de lixos, observações das raízes dos mangues, operações matemáticas, o encontro das águas do rio com a água do mar, a observação da biota da região terrestre e aquática (botânica e zoologia), entre outros conteúdos. Os grupos também abordaram os aspectos socioambientais e socioculturais locais, como a prática artesanal pesqueira, a cultura do congo e o uso racional da praia pelo o homem. 
Figura 1: Mapa da região da escola obtido pelo "Google Map" durante um trabalho realizado com os estudantes no laboratório de informática. Fonte: Banco de imagens do grupo de pesquisa.
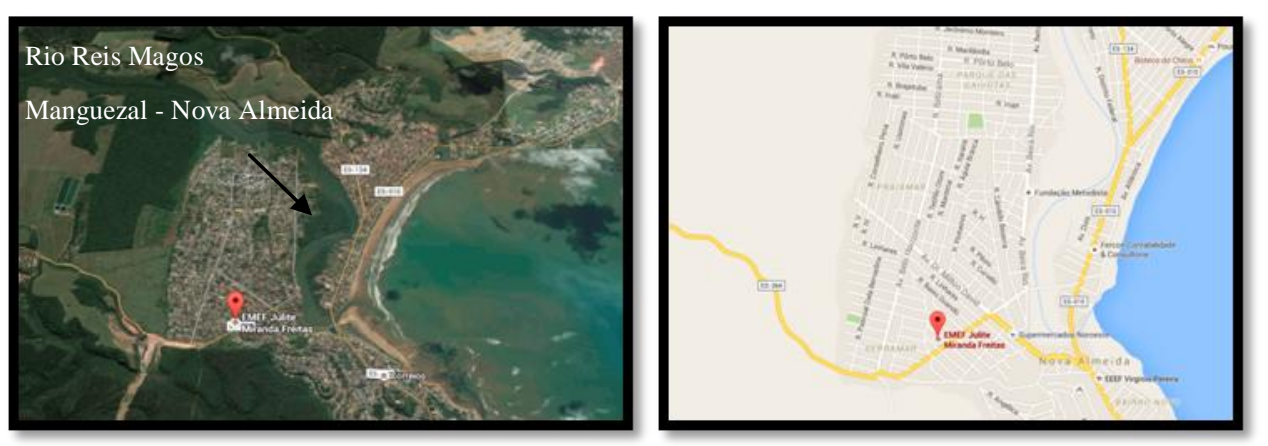

Ao estudar a prática ambiental abordando saberes escolares, populares e científicos, a partir das temáticas de "manguezal", "pesca artesanal" e "sustentabilidade", buscamos nos aproximar de temas transversais, numa perspectiva interdisciplinar e transdisciplinar. Os temas transversais (BRASIL, 1997) são constituídos pelos parâmetros curriculares nacionais $(\mathrm{PCN})$ e compreendem seis áreas: ética (respeito mútuo, justiça, diálogo, solidariedade), orientação sexual (corpo: matriz da sexualidade, relações de gênero, prevenções das doenças sexualmente transmissíveis), meio ambiente (os ciclos da natureza, sociedade e meio ambiente, manejo e conservação ambiental), saúde (autocuidado, vida coletiva), pluralidade cultural (pluralidade cultural e a vida das crianças no Brasil, constituição da pluralidade cultural no Brasil, o ser humano como agente social e produtor de cultura, pluralidade cultural e cidadania) e trabalho e consumo (relações de trabalho; trabalho, consumo, meio ambiente e saúde; consumo, meios de comunicação de massas, publicidade e vendas; direitos humanos, cidadania). Além disso, há também os temas locais como: trabalho, orientação para o trânsito, etc.

Muitas das vezes a escola está tão preocupada com o cumprimento de currículos disciplinares, que nem sempre é possível (ou está aberta) a produzir práticas pedagógicas interdisciplinares e transdisciplinares. Entretanto, com a publicação das Diretrizes Curriculares Nacionais para Educação Básica (BRASIL, 2013), que trata de diretrizes voltadas para uma educação básica com qualidade social, parece que os temas transversais e práticas interdisciplinares e transdisciplinares ganharam maior importância no cenário da escola, enfatizando práticas que levem em consideração, de alguma forma, a articulação entre trabalho, educação, ciência, tecnologia, cultura, sustentabilidade e direitos humanos. Foi com essa proposta que procuramos desenvolver o projeto escolar "Manguezal".

\subsection{A totalidade, a sustentabilidade e o projeto escolar "Manguezal"}

Para discutir a perspectiva da totalidade, nos apropriamos do conceito de totalidade proposto por Santos (1977), que em seu livro "A totalidade do diabo: economia espacial", faz uma grande crítica ao modelo capitalista e um alerta sobre seus efeitos na sociedade. Usando o termo "totalidade do diabo", o autor faz alusão aos terríveis efeitos do sistema econômico imposto à sociedade, produzindo desigualdades sociais, o mau aproveitamento do espaço territorial, a concentração de renda, a busca por mais lucro e o abandono aos pobres entre outros e algumas empresas dividem o trabalho de produção de modo desumano. Ao pensar nesse conceito de totalidade, procuramos estender o conceito de sustentabilidade na perspectiva da totalidade, 
considerando uma prática pedagógica desenvolvida num espaço de educação não formal, isto é, numa prática além da sala de aula.

De acordo com Sachs (1993), é importante desenvolver uma visão holística dos problemas da sociedade, em contraposição da visão reducionista focada apenas na gestão dos recursos naturais. Assim, esse autor propõe cinco dimensões do ecodesenvolvimento de sustentabilidade, isto é, categorias que nos levam a produzir uma sustentabilidade na sua forma mais ampla de visão de mundo, a saber: (1) Sustentabilidade Social, (2) Sustentabilidade Econômica, (3) Sustentabilidade Ecológica, (4) Sustentabilidade Espacial, e (5) Sustentabilidade Cultural. Embora o autor mais recentemente discuta 7 dimensões (SACHS, 2007), no presente trabalho nos limitamos a analisar o potencial pedagógico na perspectiva da totalidade, com base nas 5 dimensões do ecodesenvolvimento de sustentabilidade (quadro 3).

Quadro 3: Análise da aula de campo à luz das cinco categorias da sustentabilidade de Sachs (1997).

\begin{tabular}{|l|l|}
\hline $\begin{array}{l}\text { Categorias } \\
\text { de Sustentabilidade } \\
\text { de Sachs (1997) }\end{array}$ & $\begin{array}{l}\text { Contexto } \\
\text { Momentos da Aula de Campo }\end{array}$ \\
\hline $\begin{array}{l}\text { (1) Sustentabilidade } \\
\text { Social. }\end{array}$ & $\begin{array}{l}\text { Durante a visita ao rio Reis Magos, os estudantes produziram rodas de conversa } \\
\text { com os pescadores, abordando as tecnologias artesanais locais, os saberes } \\
\text { populares surgiram ao longo das conversa. A produção de fotografias e relatórios } \\
\text { oriundos do processo de coleta perpassou por questões socioculturais, abordando } \\
\text { os eventos religiosos e a cultura local e regional relacionada à pesca. }\end{array}$ \\
\hline (2) Sustentabilidade \\
Econômica. & $\begin{array}{l}\text { Durante a visita ao rio Reis Magos, os estudantes perceberam o prejuízo relativo } \\
\text { ao descaso ambiental, o crescimento desordenado e os impactos ambientais. } \\
\text { Também foram abordadas as espécies de peixe de maior valor agregado, o custo } \\
\text { da pesca, a necessidade de manutenção dos barcos, reposição dos materiais de } \\
\text { pesca e valor final do peixe que é vendido no mercado local. }\end{array}$ \\
\hline $\begin{array}{l}\text { (3) Sustentabilidade } \\
\text { Ecológica. }\end{array}$ & $\begin{array}{l}\text { Durante a visita ao rio Reis Magos, os estudantes perceberam as questões } \\
\text { ambientais, o assoreamento do rio, o crescimento desordenado e os impactos } \\
\text { ambientais. Também foram abordadas as espécies botânicas do manguezal e a } \\
\text { estrutura do mangue. A relação simbiótica entre berço da biota aquática e as } \\
\text { plantas do manguezal. A produção de caranguejos e o manguezal. }\end{array}$ \\
\hline (4) Sustentabilidade & $\begin{array}{l}\text { Durante a etapa de pré-campo, a utilização do mapa no Google foi fundamental } \\
\text { para dar a dimensão do espaço ocupado pelo manguezal e o rio dos Reis Magos. } \\
\text { Foi debatido o percurso do barco que levou os estudantes pelo rio a dentro. As } \\
\text { observações dos espaços costeiros, as áreas de transição seguida da vegetação da } \\
\text { Mata Atlântica. }\end{array}$ \\
\hline $\begin{array}{l}\text { (5) Sustentabilidade } \\
\text { Cultural. }\end{array}$ & $\begin{array}{l}\text { Durante a visita ao rio Reis Magos, os estudantes produziram conversa com os } \\
\text { pescadores, fotografias e relatos do processo de observação e coleta, perpassando } \\
\text { por questões socioculturais, abordando os eventos religiosos e a cultura local e } \\
\text { regional relacionada à pesca. }\end{array}$ \\
\hline
\end{tabular}

Leff (2002) cita que o conceito de sustentabilidade surgiu nas últimas décadas do século $\mathrm{XX}$, com o objetivo de traduzir várias ideias e preocupações devido à gravidade dos problemas ambientais e econômicos e causavam, e ainda causam, riscos às condições de vida no planeta. A Conferência de Estocolmo de 1972, realizada pela organização das Nações Unidas com a participação de 113 países, em Estocolmo, capital da Suécia. Talvez, esse evento tenha sido o grande marco inicial para se discutir sustentabilidade, abordando problemas ambientais decorrentes da poluição atmosférica, crescimento populacional e crescimento versus desenvolvimento. Durante a conferência foi concebido um importante documento político chamado "Declaração da Conferência das Nações Unidas sobre o Meio Ambiente Humano" (ONU, 1972). 
Com análise dos dados à luz da perspectiva da sustentabilidade na sua totalidade, foi possível sincronizar alguns momentos da aula de campo com as respectivas categorias de sustentabilidade de Sachs (1997), não abordou somente os aspectos ecológicos, mas, indicando que a prática pedagógica foi realizada na perspectiva da totalidade. Nesse sentido, conforme Santos (1977), buscamos identificar os conflitos e as contradições por meio do estudo das interações da prática pedagógica, recupera-se a totalidade social (movimento, conflitos, contradições), evidenciando a identidade dos moradores e produzindo um o sentimento de pertencimento local e regional.

\subsection{Interdependência entre o meio natural, o socioeconômico e o cultural}

Quando o barco de pescadores saiu às $9 \mathrm{~h}$ da Praça dos Pescadores de Nova Almeida, os estudantes produziram registros de toda aula de campo, por meio de anotações e fotografias, intermediando por observações e questionamentos. Foi possível observar a estrutura do ecossistema, ocupação humana e impactos ambientais negativos. A figura 2 mostra alguns momentos da etapa de Campo do projeto escolar "Manguezal" no rio Reis Magos, de novembro de 2012 a fevereiro de 2013.

Por exemplo, a fotografia 01 (figura 2) mostra o momento da saída do barco no cais do porto da Praça dos Pescadores em Nova Almeida, evidenciando a participação de meninas e meninos na prática pedagógica. O que ora parecia um passeio para alguns estudantes, ora passou a ser uma oporutnidade de compreensão da pesca artezanal e sua relação com a comunidade local.

Já na fotografia 02 (figura 2), que retrata um dos momentos em que os estudantes evidenciaram o problemas do crescimento desordenado da cidade invadindo o rio, com os impactos ambientais sobre o rio Reis Magos e o manguezal. Rodrigues (2010), as médias e grandes cidades brasileiras, na sua quase totalidade, surgiram e cresceram sem o devido planejamento efetivo para a conservação das áreas verdes, arborização das ruas e construção de parques e praças. Segundo a autora, com o desenvolvimento das atividades econômicas a apropriação dos espaços tornou-se cada vez mais intensa e rápida. Áreas de vegetação natural cederam lugar para o desenvolvimento das áreas urbanas ocasionando graves impactos ambientais. Conforme Layrargues (2011), a educação ambiental deve ser abordada muito além da natureza, da visão ecológica, mas deve também agregar discussões sobre os aspectos sociais. Nesse sentido, nenhuma discussão a respeito das metas, objetivos e avaliação da educação ambiental que mereça credibilidade pode deixar de abordar a perspectiva sociológica da educação como um instrumento ideológico das condições sociais.

Um ponto importante na prática ambiental foi quando os estudantes simularam um processo de construção social da ciência e tecnologia, com a discussão sobre o tamanho adequado do peixe para ser pescado. Após a realização da pesca de alguns espécimes, os estudantes produziram um mini relatório contendo a espécie do peixe, características principais (e.g., cor, tipo de escama) e o tamanho do peixe. Na fotografia 03 (figura 2) mostra o momento da medição de um peixe pescado no rio Reis Magos. Neste momento, os estudante simularam uma situação hipotética de produção de conhecimento desenvolvido por grupos de investigação junto às universidades e centros de pesquisa científica.

Segundo Sacramento-Soares e Martins-Pinheiro (2010), o rio Reis Magos faz parte da bacia hídrica da região central-norte do Estado do Espírito Santo, que desemboca na praia de Nova Almeida, dividindo o município da Serra e o município de Fundão, Espírito Santo. Antes da ocupação de Nova Almeida, este rio compunha a 
planície balneária, de relevo suave, com cursos da água com direcionamento variável. No baixo curso do rio Reis Magos, que seguia meandrando através da planície inundável, marcada por brejos e várzeas. Atualmente, o canal principal foi retificado e a várzea drenada. Próximo à foz, no balneário de Nova Almeida, ainda existe um complexo estuarino com a presença de vegetação de manguezal. O termo "mangue" também se aplica às espécies de vegetais arbóreas características oriundos do habitat de transição entre a praia e a Mata Atlântica. Ao contrário do que acontece em praias arenosas e dunas, a cobertura vegetal do manguezal instala-se em substratos de vasa de formação recente, de pequena declividade, sob a ação diária das marés de água salgada ou, pelo menos, salobra.

Figura 2: Momentos da etapa de Campo do projeto escolar "Manguezal" no rio Reis Magos, de novembro de 2012 a fevereiro de 2013. Foto 1: Saída do barco no cais do porto da Praça dos Pescadores. Foto 2: O horizonte do rio. Foto 3: Medindo o tamanho do peixe pescado no rio Reis Magos. Foto 4: O crescimento desordenado da cidade invadindo o rio. Fonte: Banco de imagens do grupo de pesquisa.

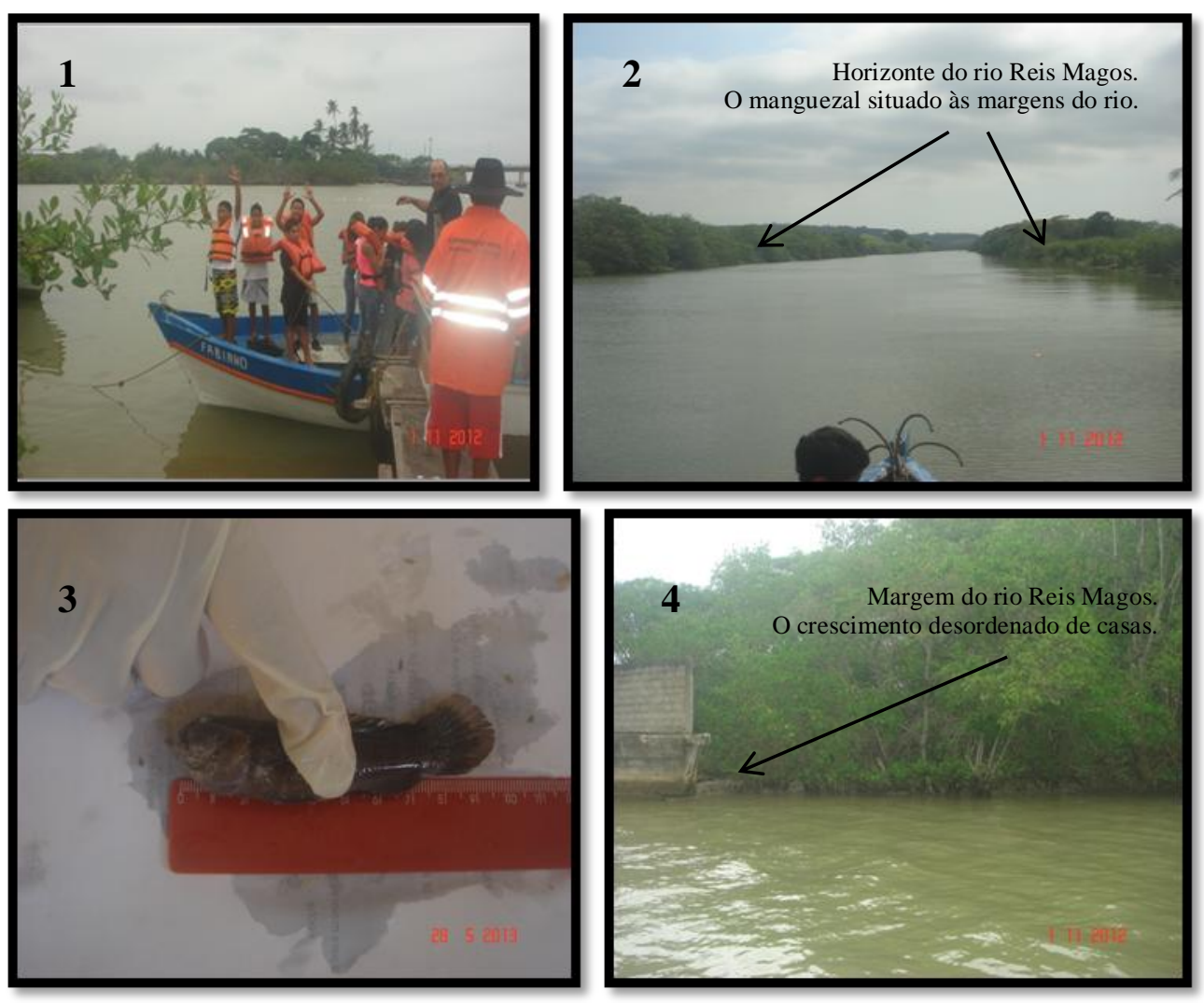

Os estudantes também coletaram o lixo espalhado no manguezal, como materiais de vidros e plásticos, o que evidenciou que nem o manguezal nem o rio Reis Magos era limpo por algum tempo. Nas rodas de conversa sobre a presença do lixo no manguezal, surgiram hipóteses de que o mesmo poderia ter vindo na correnteza do rio, em dias de chuva, muito relacionado à questão da sociedade de consumo. Mas, também, houve a hipótese do descaso das autoridades no processo de limpeza das áreas do rio e manguezal. Entretanto, houve quem comentasse a necessidade de se formar as comunidades do entorno do rio Reis Magos para servir como "fiscais do bairro" e dos "serviços públicos".

Segundo Zacarias (2009), a questão do consumo vem sendo pauta de estudos científicos no campo da educação ambiental. Entretanto, as pesquisas com maior recorrência está no campo dos estudos culturais e das teorias da pós-modernidade. 
Entretanto, para entender as mediações existentes entre produção e consumo, Marx (1982) ressalta que a produção fornece os materiais, o objeto, mas não somente o objeto que a produção cria para o consumo, uma vez que determinada também seu caráter, dá o seu acabamento e o modo de consumo. Para se entender o processo de produção capitalista é importante clarificar como se dá o processo de produção, de distribuição, de circulação e de consumo nessa sociedade.

Quando foi realizado o recolhimento do lixo espalhado no rio e nas margens, tais como plásticos, vidros, papelão, sapato entre outros, ficou evidente o processo de consumo e os impactos de uma "civilização sem cidadania". Nas rodas de conversa com os estudantes, tentou-se produzir articulações entre o processo de poluição, de educação, e do processo de consumo. A ideia foi discutir um pouco sobre a balança entre produção e consumo, perpassando pela necessidade de haver um equilíbrio para a sustentabilidade das condições de vida na terra.

\subsection{Vinculação entre ética, educação, trabalho e práticas sociais}

Para tratar a relação entre a ética, educação, trabalho e as práticas sociais, buscamos nos apropriar dos debates sobre o movimento Ciência-Tecnologia-SociedadeAmbiente (CTS/CTSA), tal como é relatado por pesquisadores como Santos e Auler (2011) e Aikenhead (2009). De acordo com Santos e Auler (2011), no Brasil, o movimento CTS/CTSA ganhou fôlego no início nos anos 90, com a criação de grupos de investigação de educação científica que abordavam a perspectiva CTS. Mas, com o agravamento dos problemas ambientais e da crise de alguns setores da economia, outros movimentos se aproximaram do movimento CTS, tais como o de Educação Ambiental (EA) e o de Educação para o Desenvolvimento Sustentável (EDS), de tal forma que alguns grupos passaram a adotar a sigla CTSA, em vez de CTS, a fim de ressaltar as questões socioambientais (VILCHES; GIL-PÉREZ; PRAIA, 2011, p. 161). Esses são os argumentos que levaram o nosso grupo de investigação a assumir a perspectiva ambiental articulada ao movimento CTS, passando a adotar a sigla CTSA.

Sadler (2011) destaca que o desenvolvimento de projetos escolares de forma interdisciplinar e transdisciplinar, abordando temas sociocientíficos, tais como alimentos transgênicos, agrotóxicos em alimentos, poluição dos rios e mares, entre outros, é uma das formas de aproximar a escolar das questões locais e regionais. Por isso que autores como Reis e Galvão (2008), defendem a discussão de temas sociocientíficos nos currículos das disciplinas científicas, às vezes apresentados na forma de controvérsias para evidenciar contradições, a fim de forçar os estudantes a se posicionarem uma ou mais situações sociocientíficas. No nosso caso, buscamos promover debates orientados pela macro temática sociocientífica de "manguezal", "pesca artesanal" e "sustentabilidade", numa escola pública de ensino fundamental.

No quadro 4 está apresentada uma análise da prática ambiental produzida à luz das categorias da educação CTS/CTSA. A análise da prática ambiental perpassou por aspectos tecnológicos, sociocientíficos, socioculturais, sócio-históricos, socioeconômicos e socioambientais, cujos olhares teve inspiração em Santos e Auler (2011), e Aikenhead (2009), mostrando uma evidente correlação da prática pedagógica com a educação CTS/CTSA.

Ao realizamos a prática ambiental, buscamos perpassar por diferentes aspectos, por exemplo, ao discutir sobre a tecnologia da pesca artesanal, a ciência envolvida no ciclo da pesca e sua relação com o manguezal, a economia local no processo de compravenda do pescado, a cultura e costumes das comunidades pesqueiras, e as práticas 
ambientais para manter o manguezal e a pesca artesanal. Durante a intervenção pedagógica, buscou-se discutir um pouco sobre o processo de construção social de ciência e tecnologia a partir da tecnologia artesanal pesqueira. A partir da experiência de pesca realizada pelos estudantes, foi possível discutir, por exemplo, a tecnologia de pesca, o processo de conserva do peixe por meio de acomodação em caixas contendo gelo pelo abaixamento da temperatura, o processo de poluição por ação antrópica, a decomposição do plástico na natureza, a alteração do $\mathrm{pH}$ e do equilíbrio da biota aquática pela introdução de águas residuárias domésticos ou industriais nos rios, entre outras questões. Desta forma, procurou-se introduzir o enfoque CTS/CTSA na intervenção pedagógica.

Quadro 4: Análise da intervenção pedagógica com base nas categorias da educação CTS/CTSA. Adaptação de Santos e Auler (2011) e Aikenhead (2009).

\begin{tabular}{|l|l|}
\hline $\begin{array}{l}\text { Educação } \\
\text { CTS/CTSA }\end{array}$ & $\begin{array}{l}\text { Contexto } \\
\text { Momentos da Aula de Campo }\end{array}$ \\
\hline $\begin{array}{l}\text { Aspectos } \\
\text { Tecnológicos }\end{array}$ & $\begin{array}{l}\text { Durante o projeto escolar foi possível perpassar pela tecnologia do processo de pesca } \\
\text { artesanal, tecnologia de recuperação dos sistemas costeiros impactados pela poluição, } \\
\text { tecnologia de identificação dos tipos de poluição no sistema hídrico e no manguezal, } \\
\text { navegação e os equipamentos utilizados na pesca artesanal, etc. }\end{array}$ \\
\hline $\begin{array}{l}\text { Aspectos } \\
\text { Sociocientíficos }\end{array}$ & $\begin{array}{l}\text { Durante o projeto escolar foi possível perpassar pela compreensão das ciências } \\
\text { biológicas do manguezal, equilíbrio ecológico do manguezal-rio-mar, a ciência das } \\
\text { embarcaçóes pequenas, a ciência do época de defeso, as ciências químicas da água } \\
\text { (pH, acidez, teor de matéria orgânica DBO/DQO), biota dos rios e do solo (vegetais, } \\
\text { algas, peixes, caramujos, caranguejos, etc.). }\end{array}$ \\
\hline $\begin{array}{l}\text { Aspectos } \\
\text { Socioculturais }\end{array}$ & $\begin{array}{l}\text { Durante o projeto escolar foi possível perpassar pela cultura do processo de pesca do } \\
\text { rio e do mar, cultura do período do defeso, comidas típicas, crenças e lendas locais, } \\
\text { tradição das festas, alimentação industrializada e artesanal, etc. }\end{array}$ \\
\hline $\begin{array}{l}\text { Aspectos } \\
\text { Sócio-históricos }\end{array}$ & $\begin{array}{l}\text { Durante o projeto escolar foi possível perpassar pela história do Espírito Santo e do } \\
\text { Brasil, período da escravidão e o trabalho escravo contemporâneo, a história das } \\
\text { crenças e religiões, a história e memórias das pessoas do local, etc. }\end{array}$ \\
\hline $\begin{array}{l}\text { Aspectos } \\
\text { Socioeconômicos }\end{array}$ & $\begin{array}{l}\text { Durante o projeto escolar foi possível perpassar pelas questões econômicas do } \\
\text { processo de artesanal pesqueira do rio e do mar, o valor agregado no peixe, o valor } \\
\text { de diferentes peixes, o mercado local e as pescarias, etc. }\end{array}$ \\
\hline $\begin{array}{l}\text { Aspectos } \\
\text { Socioambientais }\end{array}$ & $\begin{array}{l}\text { Durante o projeto escolar foi possível perpassar pelas questões ambientais do } \\
\text { processo de artesanal pesqueira do rio e do mar, o ciclo da pesca, os problemas de } \\
\text { saúde, a poluição de rios e de solo, as pragas, etc. }\end{array}$ \\
\hline
\end{tabular}

Baseado em Aikenhead (2009), ao desenvolver uma prática pedagógica com enfoque CTS/CTSA, buscamos articular conteúdos programáticos de ciências naturais às questões sociocientíficas, envolvendo a macro temática sociocientífica de "manguezal", "pesca artesanal" e "sustentabilidade", dando sentido aos saberes escolares, científicos e populares. Assim, a partir desta análise, é possível afirmar que a prática ambiental contribuiu na formação dos estudantes produzindo indivíduos autônomos, reconhecendo a importância local e regional em suas vidas, reconhecendo a importância da tecnologia, ciência, economia, cultura e ambiente, não de forma neutra e salvacionista, mas com possibilidades de melhorar a qualidade de vida das pessoas, e, talvez, tenha contribuído para promover sua cidadania ao longo da vida. 


\subsection{Uma perspectiva crítica e transformadora dos desafios ambientais}

Nos meses de novembro e dezembro de 2012 foram realizadas rodas de conversa que duravam 2 horas cada (pós-campo), envolvendo os estudantes do ensino fundamental que participaram do projeto escolar "Manguezal". Na figura 3 mostra um momento das rodas de conversa que ocorreu no laboratório de informática da escola. Durante esta roda de conversa, a professora projetou fotografias e transparências contendo um resumo da etapa de Campo realizada anteriormente, promovendo debates e discussões, entrelaçando conteúdos programáticos com as observações produzidas durante a prática pedagógica. À medida que a roda de conversa transcorria, os estudantes preenchiam um formulário contendo perguntas sobre a prática pedagógica realizada, conforme é apresentado a seguir:

Como é o solo? Descreva algumas características.

Como são as árvores? Descreva algumas características, tais como folhas e raízes.

Qual a aparência da água? Descreva.

Algum animal foi observado? Cite quais foram? Descreva.

Esse ecossistema sofreu impactos negativos? Sim ou Não?

Cite alguns impactos negativos no ecossistema que foram observados durante a aula de campo?

Figura 3: Um roda de conversa realizada no laboarório de informática da escola. Um momento do Póscampo do projeto escolar "Manguezal". Fonte: Banco de imagens do grupo de pesquisa.

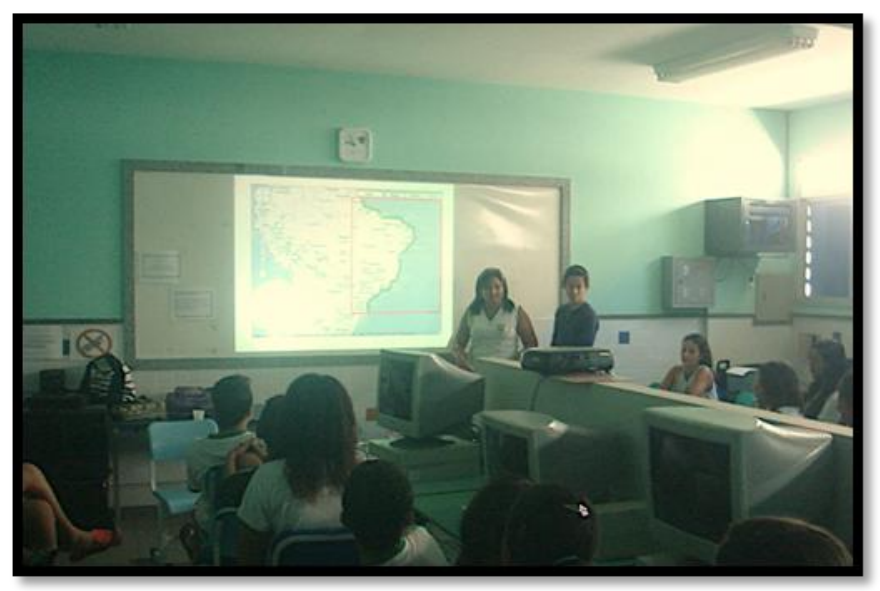

Houve um momento da roda de conversa que surgiram debates sobre as características do ecossistema e a manutenção da atividade de pesca. Durante o debate, foi possível reviver/redimensionar alguns conteúdos programáticos, escolares e não escolares, isto é, diferentes saberes escolares, populares e científicos, antes vistos separadamente na disciplina de ciências naturais. Por exmplo, houve uma discussão sobre a identidade cultural, abordando a condição de ser filho de pescador e a oportunidade de contribuir com sua comunidade. Constatou-se que os estudantes se sentiam envergonhados por relatarem sua origem e seu vínculo com a comunidade de pescadores.

Nesse momento, buscamos abordar a questão de sentimento de pertencimento e da identidade cultural, envolvendo as temáticas de inclusão e exclusão social, emancipação, cidadania, diversidade e diferença. Segundo Sousa (2010), a temática do sentimento de pertencimento tem ainda sua atualidade e sua complexidade marcadas pela presença dos meios de comunicação atuando no imaginário social, nas diferentes 
formas de organização da vida individual e coletiva, na delimitação e criação de interesses que os condicionam. Os diferentes mediam podem, pois, estar atuando como mediação fundamental tanto na construção quanto na caracterização do pertencimento como linguagem de busca de identidade no contexto de um ausente comum aglutinador. Ainda segundo o autor, uma sociedade que convive, ao mesmo tempo, com processos de fragmentações crescentes da vida individual e coletiva e com processos políticos, econômicos e culturais da globalização.

Parece que, nesse cenário de crise socioambiental em que vivemos, segundo Lima (2011, p. 116), há um olhar impressionista sobre o desenrolar da história moderna que permite-nos entrever passagens significativas que marcaram a trajetória da cultura ocidental em sua relação com o meio ambiente natural e construído. O que poderia ser motivo de orgulho para os alunos de fazerem parte da história local da comunidade de pescadores, parece representar algo sem importância.

Mas, a aula de campo buscou mostrar o lado sociocultural do processo da pesca artesanal, da comunidade de pescadores, do manguezal e do rio Reis Magos, e, talvez, esses debates tenham feito diferença na vida daquelas crianças. Tristão (2012, p. 236), ao discutir as dimensões e os desafios da educação ambiental na contemporaneidade, ressalta que os conceitos entrelaçados no processo de educação ambiental, como autoorganização, complexidade, holismo e multirreferencialidade, extrapolam os limites das disciplinas que os engendraram. São transversais, pois atravessam vários campos do conhecimento.

A partir da etapa de pós-campo, foi possível promover uma perspectiva crítica e transformadora de desafios ambientais a serem enfrentados pelas atuais e futuras gerações, nas dimensões locais, regionais, nacionais e globais. Sato e Carvalho (2005) ressaltam que as atividades educacionais alternativas permitem a avaliação do estudante por sua atitude, comportamento ou atuação participativa. E, ainda, reforça que a escola deve incentivar a produção de conhecimento a partir de questões locais e regionais, tornando os educandos críticos para que possam transformar as sociedades.

\subsection{Respeito à pluralidade $\mathrm{e}$ à diversidade}

A roda de conversa realizada alguns dias após a aula de campo, produziram alguns debates enfatizou a diversidade ecológica do manguezal, da relação ecológica entre o rio e o mar, e da biota dos ambientes costeiros, por exemplo, os peixes, os caranguejos e os vegetais. Entretanto, a diversidade das relações sociológicas estabelecidas na escola com os colegas, de diferentes origens e localidades, e a consciência das relações estabelecidas entre pescadores e pessoas locais também produziu uma reflexão sobre a pluralidade sociológica do ambiente vivido pelos estudantes do ensino fundamental.

No quadro 5 mostra o resultado de uma análise da prática ambiental à luz das categorias da educação não formal de Gohn (2006). Foi possível encontrar características da proposta da educação não formal nos momentos da aula de campo, tais como a promoção de saberes relacionados ao aprendizado das diferenças, onde se aprende a conviver com os demais, socializando-se o respeito mútuo. Também, foi possível constatar contribuições da prática ambiental na adaptação do grupo a diferentes culturas por meio do reconhecimento dos indivíduos e do papel do outro; e na construção da identidade coletiva de um grupo. Assim, foi possível perceber o respeito à pluralidade e à diversidade, seja individual, seja coletiva, étnica, racial, social e cultural, 
disseminando os direitos de existência e permanência e o valor da multiculturalidade e plurietnicidade do país e do desenvolvimento da cidadania planetária.

Quadro 5: Análise da prática ambiental à luz das categorias da educação não formal de Gohn (2006).

\begin{tabular}{|c|c|}
\hline $\begin{array}{l}\text { Categorias da } \\
\text { Educação Não Formal }\end{array}$ & Contexto da Aula de Campo \\
\hline $\begin{array}{l}\text { Consciência e organização de } \\
\text { como agir em grupos coletivos. }\end{array}$ & $\begin{array}{l}\text { A aula de campo promoveu a realização de estudos colaborativos e } \\
\text { cooperativos pelos estudantes do ensino fundamental, mediados pela } \\
\text { macro temática manguezal - rio - mar. Dada a extensão geográfica e a } \\
\text { complexidade da prática pedagógica, os estudantes se organizaram e } \\
\text { traçaram um itinerário dos ambientes visitados, buscando um consenso } \\
\text { nas decisões, respeito mútuo e aprendizagem colaborativa. }\end{array}$ \\
\hline $\begin{array}{l}\text { A construção e reconstrução de } \\
\text { concepções de mundo e sobre o } \\
\text { mundo; a contribuição para um } \\
\text { sentimento de identidade com } \\
\text { uma dada comunidade; forma o } \\
\text { indivíduo para a vida e suas } \\
\text { adversidades, e não apenas } \\
\text { capacita-o para entrar no } \\
\text { mercado de trabalho. }\end{array}$ & $\begin{array}{l}\text { A observação e anotações realizadas durante a aula de campo foi } \\
\text { importante para a (re)construção de novas concepções sobre a nossa } \\
\text { civilização. A interpretação dos dados e os debates realizados produziu } \\
\text { uma reflexão sobre a importância de se preservar e o papel de cada um } \\
\text { nesse processo cidadão, potencializando um sentimento de identidade } \\
\text { como uma dada comunidade - os pescadores. }\end{array}$ \\
\hline $\begin{array}{l}\text { Quando presente em programas } \\
\text { com crianças ou jovens } \\
\text { adolescentes a educação não- } \\
\text { formal resgata o sentimento de } \\
\text { valorização de si próprio (o que } \\
\text { a mídia e os manuais de } \\
\text { autoajuda denominam, } \\
\text { simplificadamente, como a } \\
\text { autoestima). }\end{array}$ & $\begin{array}{l}\text { A aula de campo potencializou o sentimento de autonomia e liberdade } \\
\text { nos estudantes, mostrando que todos nós podemos ter um papel no } \\
\text { mundo, e a importância que nós damos a ele, caberá a nós e não aos } \\
\text { outros. A experiência de saber que o manguezal é o berçário dos } \\
\text { peixes e que a renda econômica de muitos colegas da classe dependia } \\
\text { disso, mostrou a importância de se valorizar cada um indivíduo da } \\
\text { comunidade. }\end{array}$ \\
\hline $\begin{array}{l}\text { Condições aos indivíduos para } \\
\text { desenvolverem sentimentos de } \\
\text { auto valorização, de rejeição } \\
\text { dos preconceitos que lhes são } \\
\text { dirigidos, o desejo de lutarem } \\
\text { para ser reconhecidos como } \\
\text { iguais (enquanto seres } \\
\text { humanos), dentro de suas } \\
\text { diferenças (raciais, étnicas, } \\
\text { religiosas, culturais etc.). }\end{array}$ & $\begin{array}{l}\text { A sala de aula, o encontro com as duas turmas da disciplina de } \\
\text { ciências naturais, a comunidade escolar, a comunidade pesqueira, entre } \\
\text { outros componentes, promoveu uma riqueza de diversidades e de } \\
\text { pluralidades. A convivência e o contato com diferentes indivíduos e } \\
\text { saberes possibilitou aos participantes uma ampliação da visão de } \\
\text { mundo, desconstruindo antigos dogmas e estabelecendo novos } \\
\text { paradigmas de respeito mútuo entre as diferentes identidades e grupos } \\
\text { culturais. }\end{array}$ \\
\hline $\begin{array}{l}\text { Os indivíduos adquirem } \\
\text { conhecimento de sua própria } \\
\text { prática, os indivíduos aprendem } \\
\text { a ler e interpretar o mundo que } \\
\text { os cerca. }\end{array}$ & $\begin{array}{l}\text { Os debates realizados durante a aula de campo promoveram uma } \\
\text { reflexão sobre os processos existentes na pesca artesanal e a relação } \\
\text { com o rio, o mar e o manguezal. }\end{array}$ \\
\hline
\end{tabular}

Num documento sobre educação não formal da Unesco, baseado na conferência de Dakar (UNESCO, 2001), ressalta diversos aspectos da educação não formal para realização de práticas fora do ambiente escolar, para o empoderamento e inclusão social, apropriação de culturas artísticas, científicas e tecnológicas tais como da área de alimentos, saúde, ambiental, agricultura, para produzir conexões com o mundo do trabalho, fortalecendo identidades e desenvolver cidadania (UNESCO, 2006).

A indução para estabelecer relações entre a temática estudada - manguezal, pescaria artesanal, rio e mar - e a educação não formal, potencializou produção de saberes escolares articulados aos saberes populares e científicos. Isso aconteceu principalmente na etapa pós-campo a partir da síntese dos registros, com trocas de 
experiências e avaliação dos saberes (re)significados. Houve relatos de alguns estudantes sobre quão importante foi a prática para conhecer o que seu pai fazia no seu trabalho.

\section{Considerações Finais}

O projeto escolar "Manguezal" se constituiu numa proposta metodológica de educação ambiental para articular a escola de ensino fundamental e o contexto da comunidade pesqueira de Nova Almeida do Estado do Espírito Santo. Como foi evidenciada nas rodas de conversa, foi possível confrontar saberes escolares, científicos e populares, a partir das experiências pedagógicas, promovendo a ampliação da visão de mundo. Por exemplo, por questões da tecnologia pesqueira, socioculturais, sóciohistóricas, geografia pesqueira, matemática, ciências naturais e socioambientais.

A aula de campo do projeto "Manguezal" produziu diálogos entre ambientes formais e não formais, evidenciando os aspectos da identidade cultural da prática da pesca artesanal. Foi possível produzir uma articulação entre teoria e prática (práxis pedagógica) quando os estudantes produziram os relatórios a partir das observações e realização da coleta materiais plásticos, vidro, papelão, descartes domésticos, entre outros. Os estudantes perceberam a importância da prática da pesca artesanal e os fatores que podem favorecer para a manutenção desta prática cultural. Também, foi possível promover o sentimento de pertencimento, desenvolvendo iniciativas para o cuidado local e regional.

A prática ambiental promoveu uma série de debates importantes para o desenvolvimento humano e econômico, cujo processo educativo esteve centrado nos pilares do saber ser, saber fazer, saber conhecer e saber conviver, de maneira geral, integrando os constructos das relações sociais diretas e do desenvolvimento humano individual (DELORS, 1996). Para isso, a aula de campo foi planejada com base em Seniciato e Cavassan (2004), desenvolvida além da sala de aula e abordou aspectos interdisciplinares e transdisciplinares mediados pelas temáticas "manguezal", "pesca artesanal" e "sustentabilidade".

A análise dos aspectos da sustentabilidade, perpassando pelas cinco categorias de Sachs (1997), isto é, abordando não só aspectos ecológicos, mas também aspectos sociais, econômicos, espaciais e culturais. Nesse sentido, conforme Santos (1977), buscamos debater os conflitos e as contradições por meio do estudo das interações da prática pedagógica, recupera-se a totalidade social (movimento, conflitos, contradições). Assim, esse autor propõe cinco dimensões do ecodesenvolvimento de sustentabilidade, isto é, categorias que nos levam a produzir uma sustentabilidade na sua forma mais ampla de visão de mundo, a saber: (1) Sustentabilidade Social, (2) Sustentabilidade Econômica, (3) Sustentabilidade Ecológica, (4) Sustentabilidade Espacial, e (5) Sustentabilidade Cultural.

A análise dos aspectos pedagógicos tendo em vista a educação não formal de Gohn (2006), evidenciou várias potencialidades da prática pedagógica, tais como a promoção de saberes relacionados ao aprendizado das diferenças, onde se aprende a conviver com os demais, socializando-se o respeito mútuo; a adaptação do grupo a diferentes culturas por meio do reconhecimento dos indivíduos e do papel do outro; a construção da identidade coletiva de um grupo; e o balizamento de regras éticas relativas às condutas aceitáveis socialmente.

O relatório da Unesco sobre os avançados alcançados por 164 países do acordo de Dakar - "Marco de Ação de Dakar, Educação para Todos (EPT): Cumprindo nossos 
Compromissos Coletivos", expresso no documento da Unesco (2001), apontou que, nos últimos 15 anos, o Brasil só cumpriu duas das seis metas fixadas em 2000 (UNESCO, 2015). Considerando que os estudantes são do ensino fundamental, procuramos nos alinhar dos debates travados no acordo "Educação 2030: Declaração de Incheon e Marco que no Brasil" (UNESCO, 2016), que referencia a educação não formal como importante modalidade para promover a aprendizagem ao longo da vida, flexibilidade na aprendizagem tanto no nível primário quanto no secundário, na educação e formação técnica e profissional (EFTP), e na produção de educação para o desenvolvimento sustentável (EDS) e educação para cidadania global (ECG). Ressalta-se alguns aspectos da educação não formal produzidos durante a prática, como a apropriação de culturas populares e tecnológicas, tais como tecnologia artesanal pesqueira, comidas típicas, embarcações e navegação no rio, para produzir conexões com o mundo do trabalho e promover cidadania (UNESCO, 2006).

Com base nos princípios estabelecidos nas Diretrizes Curriculares Nacionais para a Educação Ambiental (BRASIL, 2012), produzidos a partir da Lei Federal № 9.795/1999, foi possível correlacionar os momentos da aula de campo com as categorias, a saber: I - totalidade como categoria de análise fundamental em formação, análises, estudos e produção de conhecimento sobre o meio ambiente; II interdependência entre o meio natural, o socioeconômico e o cultural, sob o enfoque humanista, democrático e participativo; IV - vinculação entre ética, educação, trabalho e práticas sociais na garantia de continuidade dos estudos e da qualidade social da educação; V - articulação na abordagem de uma perspectiva crítica e transformadora dos desafios ambientais a serem enfrentados pelas atuais e futuras gerações, nas dimensões locais, regionais, nacionais e globais; VI - respeito à pluralidade e à diversidade, seja individual, seja coletiva, étnica, racial, social e cultural, disseminando os direitos de existência e permanência e o valor da multiculturalidade e plurietnicidade do país e do desenvolvimento da cidadania planetária.

As Diretrizes Curriculares Nacionais do Ensino Fundamental (BRASIL, 2013), que trouxeram os fundamentos para a educação básica com qualidade social, preconizam, entre outras coisas, a relação entre a educação, ciência, tecnologia e cultura, relacionando os direitos humanos e a sustentabilidade como princípio pedagógico na educação básica. Além disto, com relação ao Plano Nacional da Educação (PNL) com suas 20 metas estruturantes para a garantia do direito à educação básica com qualidade, ressaltam-se as metas que relacionam o ensino fundamental ao contexto da educação não formal, considerando as demandas locais e regionais (BRASIL, 2014). Nesse sentido, a realização deste estudo buscou inovar práticas escolares no âmbito das Ciências Naturais, promovendo a articulação entre educação, trabalho, ciência, tecnologia e cultura para que, talvez, isso possa repercutir na vida dos jovens da educação básica.

\section{Agradecimentos}

Os autores agradecem ao Programa de Pós-graduação em Educação em Ciências e Matemática do Ifes, à Secretaria Municipal de Educação de Serra-ES, ao CNPq e à Fapes pelo apoio no desenvolvimento da investigação de mestrado.

\section{Referência}

AIKENHEAD, Glen S. Educação Científica para todos. Tradução de Maria Teresa Oliveira. 1a. Edição. Mangualde - PT: Edições Pedagogo. 2009. 
ALVES, Jorge Rogério Pereira. Manguezais: Educar para proteger. Fundação de Estudos do Mar. FEMAR: SEMADS. ISBN 85-85966-21-1. 2001.96 p.

BARBOSA, Joaquim Gonçalves; HESS, Remi. O diário de pesquisa. O estudante universitário e seu processo formativo. Série Pesquisa. Volume 18. Brasília, DF: Liber Livro Editora. 2010. 103 p.

BRASIL. Lei Federal № 9.795, de 27 de abril de 1999. Dispõe sobre a educação ambiental, institui a Política Nacional de Educação Ambiental e dá outras providências. 1999.

BRASIL. Planejando a Próxima Década Conhecendo as 20 Metas do Plano Nacional de Educação. Brasília - DF: Ministério da Educação. 2014.

BRASIL. Resolução № 2, de 15 de junho de 2012. Estabelece as Diretrizes Curriculares Nacionais para a Educação Ambiental. Conselho Nacional de Educação. Brasília - DF: Ministério da Educação. 2012.

BRASIL. Secretaria de Educação Básica. Secretaria de Educação Continuada, Alfabetização, Diversidade e Inclusão. Conselho Nacional de Educação. Diretrizes Curriculares Nacionais para Educação Básica. Brasília, DF: MEC, SEB, DICEI, 2013. 542 p.

BRASIL. Secretaria de Educação Fundamental. Parâmetros curriculares nacionais: terceiro e quarto ciclos. Apresentação dos temas transversais. Secretaria de Educação Fundamental. Brasília-DF: MEC/SEF, 1998. 436 p.

CAMPOS, Carlos Roberto Pires. Aula de campo para alfabetização científica: Práticas pedagógicas escolares. Série de Pesquisas em Educação em Ciências e Matemática. Volume 06. $1^{\text {a }}$. Edição. Editora Ifes. 2015.

DELORS, J. Educação um Tesouro a Descobrir. Relatório para a UNESCO da Comissão Internacional sobre Educação para o século XXI. São Paulo, Cortez Editora. 1996, 288p.

ESPÍRITO SANTO. Lei Estadual № 9.265, de 15 de julho de 2009. Institui a Política Estadual de Educação Ambiental e dá outras providências . 2009.

GATTI, Bernadete Angelina. Grupo focal na pesquisa em ciências sociais e humanas. Série pesquisa em Educação. Volume 10. Brasília, DF: Liber Livro Editora. 2015. $75 \mathrm{p}$.

GIL, Antonio Carlos. Estudo de caso. São Paulo: Editora Atlas, 2014.

GIL, Antonio Carlos. Métodos e técnicas de pesquisa social. São Paulo: Editora Atlas. 2008.

GOHN, Maria da Glória. Educação não formal e o educador social, atuação no desenvolvimento de projetos sociais. São Paulo: Cortez. 2010.

GOHN, Maria da Glória. Educação não-formal, participação da sociedade civil e estruturas colegiadas nas escolas. Ensaio: aval. pol. públ. Educ., Rio de Janeiro, v.14, n.50, p 27-38, jan./mar. 2006.

LAYRARGUES, Philippe Pomier. Muito além da natureza: educação ambiental e reprodução social. 2011. In: LOUREIRO, Carlos Frederico B. LAYRARGUES, Philippe Pomier. CASTRO, Ronaldo Souza de. Pensamento complexo, dialética e educação ambiental. 2a. Edição. São Paulo: Editora Cortez. ISBN 978-85-249-1134-7. 2011. 
LEFF, Enrique. Saber ambiental: sustentabilidade racionalidade, complexidade, poder. $2^{\text {a }}$ ed. Rio de Janeiro: Vozes, 2002.

LIMA, Gustavo Ferreira da Costa. Crise ambiental, educação e cidadania: os desafios da sustentabilidade emancipatória. In: LOUREIRO, Carlos Frederico Bernardo; LAYRARGUES, Philippe Pomier; CASTRO, Ronaldo Souza de. Educação Ambiental: repensando o espaço da cidadania. $5^{\text {a }}$ Edição. São Paulo, SP: Editora Cortez. 2011. 263 p.

MARX, Karl. Para crítica da economia política: salario, preço e lucro. São Paulo: Abril Cultural, 1982.

ONU. Declaração da Conferência das Nações Unidas sobre o Meio Ambiente Humano. Conferência de Estocolmo. 1972.

REIS, Pedro Guilherme Rochas dos; GALVÃO, Cecília. Os professores de Ciências Naturais e a discussão de controvérsias sociocientíficas: dois casos distintos. Revista eletrônica de Enseñanza de las Ciência. v. 7, n. 3. 2008.

ROCHA, Katiuscia Soares Viana. LEITE, Sidnei Quezada Meireles. Práxis Ambiental no Manguezal de Nova Almeida do Espírito Santo com estudantes do ensino fundamental: análise pedagógica à luz da pedagogia de Moacir Gadotti. Revista da SBENBIO, N. 7. 6865-6876. Outubro, 2014.

RODRIGUES, Edilene Alves. A dinâmica do crescimento urbano na cidade de Vitória da Conquista: a verticalização e as transformações no bairro candeias. Anais do XVI Encontro Nacional de Geógrafo. Realizado de 25 a 31 de julho de 2010. Porto Alegre - RS, 2010.

SACHS, Ignacy. Estratégias de transição para o século XXI: desenvolvimento e meio ambiente. São Paulo: Nobel, 1993.

SACHS, Ignacy. Rumo à ecossocioeconomia: teoria e prática do desenvolvimento. São Paulo: Cortez, 2007.

SADLER, Troy D. (Editor). Socio-scientific Issues in the Classroom. Teaching, Learning and Research. Florida - USA: Springer. 2011. p. 375.

SANTOS, Milton. A totalidade do Diabo: Economia Espacial. São Paulo: Editora HUCITEC. 1977.

SANTOS, Wildson Luiz Pereira dos; AULER, Décio (Orgs.) CTS e educação científica. Desafios, tendências e resultados de pesquisa. Brasília: Editora UnB. 2011.

SARMENTO-SOARES, Luisa Maria. MARTINS-PINHEIRO, Ronaldo Fernando. A fauna de peixes da bacia dos Reis Magos e microbacias de Serra, Espírito Santo, Brasil. Boletim do Museu de Biologia Mello Leitão (N. Sér.) 28:105-141. 2010.

SATO, Michèle. CARVALHO, Isabel. Educação Ambiental. Pesquisa e Desafios. São Carlos, SP: Penso Editora. 2005. 232 p.

SENICIATO, Tatiana. CAVASSAN, Osmar. Aulas de campo em ambientes naturais e aprendizagem em ciências - um estudo com estudantes do ensino fundamental. Ciência \& Educação, v. 10, n. 1, p. 133-147, 2004.

SOUSA, Mauro Wilton de. O pertencimento ao comum mediático: a identidade em tempos de transição. Significação. No. 34. 2010. 
THIOLLENT, Michel. Metodologia da pesquisa-ação. $18^{\mathrm{a}}$ Edição. São Paulo, SP: Cortez Editora, 2011. 136 p.

TRISTÃO, Martha. As dimensões e os desafios da educação ambiental na contemporaneidade. In: Ruscheinsky, Aloisio (Org.). Educação Ambiental: abordagens múltiplas. 2ª . Edição. Porto Alegre: Editora Penso. 2012. 312 p.

UNESCO. Educação 2030: Declaração de Incheon e Marco que no Brasil. Brasília, DF: Unesco no Brasil, 2016.

UNESCO. Educação para todos 2000-2015: progressos e desafios. Relatório Consiso. Relatório de Monitoramento Global de EPT 2015. Unesco Brasil. Brasília, DF: Unesco no Brasil, 2015. 58p.

UNESCO. Educação Para Todos: o compromisso de Dakar. Brasília, DF: Unesco no Brasil, 2001. 70p.

UNESCO. Wim Hoppers. Non-formal education and basic education reform: a conceptual review. International Institute for Educational Planning. Unesco. 2006.

VILCHES, A.; GIL-PÉREZ, D.; PRAIA, J. De CTS a CTSA: educação por um futuro sustentável. In: SANTOS, Wildson Luiz Pereira dos, AULER, Décio. (Orgs.). CTS e educação científica: desafios, tendências e resultados de pesquisa. Brasília: Editora Universidade de Brasília, p. 161-184. 2011.

VIVEIRO, Alessandra Aparecida ; DINIZ, Renato Eugênio da Silva . Atividades de campo no ensino das ciências e na educação ambiental : refletindo sobre as potencialidades desta estratégia na prática escolar. Ciência em Tela. V. 2, N. 01. 2009.

ZACARIAS, Rachel. "Sociedade e consumo", ideologia do consumo e as iniquidades socioambientais dos atuais padrões de produção e consumo. 2009. In: LOUREIRO, Carlos Frederico B. LAYRARGUES, Philippe Pomier. CASTRO, Ronaldo Souza de. Repensar a Educação Ambiental: um olhar crítico. São Paulo: Editora Cortez. ISBN 978-85-249-1502-4. 2009. 